\title{
An optical investigation of combustion process of a direct high-pressure injection of natural gas
}

\author{
Ryosuke Ishibashi $^{1} \cdot$ Daisuke Tsuru $^{1}$
}

Received: 5 August 2014/ Accepted: 13 November 2016/Published online: 3 December 2016

(C) The Author(s) 2016. This article is published with open access at Springerlink.com

\begin{abstract}
More than $90 \%$ of worldwide cargo transportation is carried out by ships. Nowadays, a contradictory circumstance like tough exhaust emission regulations for oceangoing ships by International Maritime Organization (IMO) and deterioration in the quality of marine fuel forces some challenges. A change to another fuel, such as liquefied natural gas (LNG), is conceivable. To create ideas for such the new combustion system, it is essential to visualize the combustion process and find the actual problems. For that target, a world largest class Rapid Compression and Expansion Machine (RCEM with 200-mm-wide or 240-mmdiameter window) that holds under $20 \mathrm{MPa}$ cylinder pressure has been designed and built by the authors. This RCEM is equipped with several electronically controlled fuel injection systems for both liquid fuel and gas fuel. Characteristics of diesel spray combustion and gas injection (GI) combustion can be analyzed using direct photography and some kinds of laser optical techniques. After one-shot burning of the fuel, the burnt gas is sent from RCEM to a gas analyzer and $\mathrm{NOx}, \mathrm{CO}, \mathrm{CO}_{2}$ and THC can be measured. In this paper, a fundamental difference of combustion process between diesel and GI is made clear. However, as GI combustion emits much higher NOx than the lean-burn, some measures like EGR is necessary for the IMO Tier 3 NOx regulation. The GI combustion under EGR atmosphere (lower oxygen \%) is also visualized. Some data of GI combustion are obtained by above-mentioned experiments. However, the phenomena are too complicated. As the next task, to create and validate a calculation model is important
\end{abstract}

Daisuke Tsuru

dtsuru@ence.kyushu-u.ac.jp

1 Department of Energy and Environmental Engineering, Kyushu University, Ksuga-koen 6-1, Kasuga, Fukuoka, Japan to optimize the GI system. In this study, the three-dimensional CFD code, KIVA3V, combined with the software tool for solving complex chemical kinetics, SENKIN, was modified for GI combustion.

Keywords Gas engine - Gas direct injection · Methane · Optical engine $\cdot$ Large engine $\cdot$ Marine diesel engine

\section{Introduction}

The use of natural gas, whose main component is methane $\left(\mathrm{CH}_{4}\right)$, as a fuel for vessels is a highly promising solution to meet challenges of technical compliance requested by upcoming carbon dioxide $\left(\mathrm{CO}_{2}\right)$ and emission regulations.

The gas injection (GI) combustion system for which highpressure gas is directly injected into the cylinder is described here. In a typical low-speed two-stroke GI engine, gas at 25-30 MPa is injected through gas injection nozzles fitted on the cylinder head at the end of compression stroke; it is then ignited by a small amount of liquid fuel injected from pilot fuel injectors. The combustion pattern of a GI engine is totally different from that of what we call the premixed leanburn gas combustion; rather, it is much closer to the diffusive combustion that occurs in diesel spray combustion.

Referring to the history of GI type gas engines during the 1980s, many low-speed engine builders began developing and testing two-stroke dual-fuel (DF) engines for use on LNG carriers, so as to make it possible to burn the boiloff gas as fuel.

After the developing time, MES (Mitsui Engineering and Shipbuilding Co., Ltd) built the 12K80MC-GI-S (40 MW) engine with a bore of $800 \mathrm{~mm}$ and 12 cylinders [1]. This engine was operated for a total of $20,000 \mathrm{~h}$ during 1994-2003 as a local power station at the company's Chiba 
shipyard. The technology developed by MES has been later incorporated into the following ME-GI engine development.

At MAN Diesel \& Turbo AS, a test engine 4T50ME-X (number of cylinders: 4, bore: $500 \mathrm{~mm}$, stroke: $2200 \mathrm{~mm}$, MCR speed: $123 \mathrm{rpm}$, MCR power: $7080 \mathrm{~kW}$ ) has been converted to a GI engine and various tests related to the practical application have been conducted. The $P_{\text {me }}$ (mean effective pressure) has already reached a level of $2 \mathrm{MPa}$ [2].

However, fundamental studies [3] on the combustion process with GI system have not so often been discussed. To create the new ideas, for example, to reduce NOx emission and to improve the thermal efficiency at the same time, it is essential to clarify how the gas-jet is burning in the GI engine in detail. Moreover, the injection and mixture process of gas jet differ essentially from diesel spray process in that gas jet has no evaporation process. Self-ignition temperature of methane is much higher than that of gas oil. GI combustion requires the pilot diesel spray for ignition. Conversely, GI combustion can control the fuel-air mixing by changing the injection timing of pilot diesel spray. Therefore, this paper reveals the feature of GI combustion by comparing with diesel combustion.

For that purpose, the authors have developed a rapid compression and expansion machine (RCEM) to visualize the GI combustion process. The RCEM also helps to clarify the emission-influencing parameters such as injection condition and oxygen concentration.

In the first series of experiments, a cylinder head with a cuboid-shaped clearance volume and an observation view of $200 \mathrm{~mm}$ in width and $50 \mathrm{~mm}$ in height is applied to analyze a single GI flame. In the experiments, pure methane, the main component of natural gas, is burned and compared to the diesel spray combustion.

For the second series of experiments, the combustion chamber is replaced with a cylindrical volume simulating a current two-stroke GI engine. It is designed to allow an observation of multi-flames in swirling air through a 240-mm-dia. window.

Some data of GI combustion are obtained by abovementioned experiments. However, the phenomena are too complicated. As the next task, to create and validate a calculation model is important to optimize the GI system. In this study, the three-dimensional CFD code, KIVA3V, combined with the software tool for solving complex chemical kinetics, SENKIN, was modified for GI combustion.

\section{Rapid compression and expansion machine (RCEM)}

A single-cylinder test engine has been completely modified and converted into the rapid compression and expansion machine (RCEM). The arrangement shown in
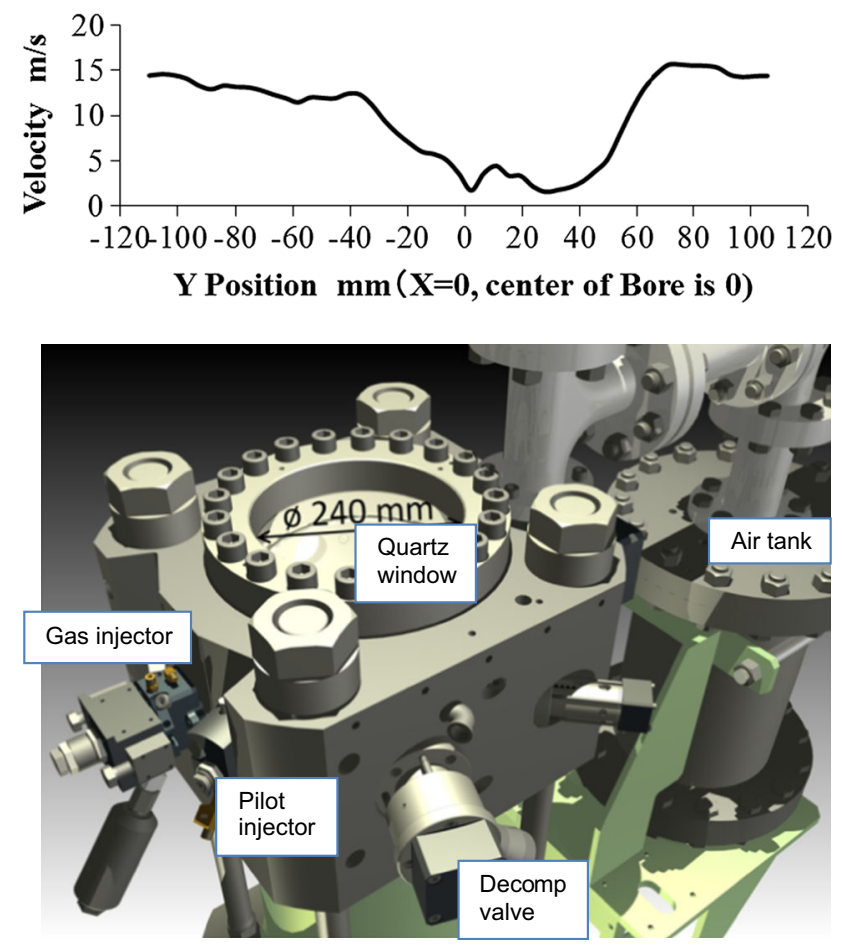

Fig. 1 Rapid compression and expansion machine (RCEM) (arrangement for top view described in Sect. 4)
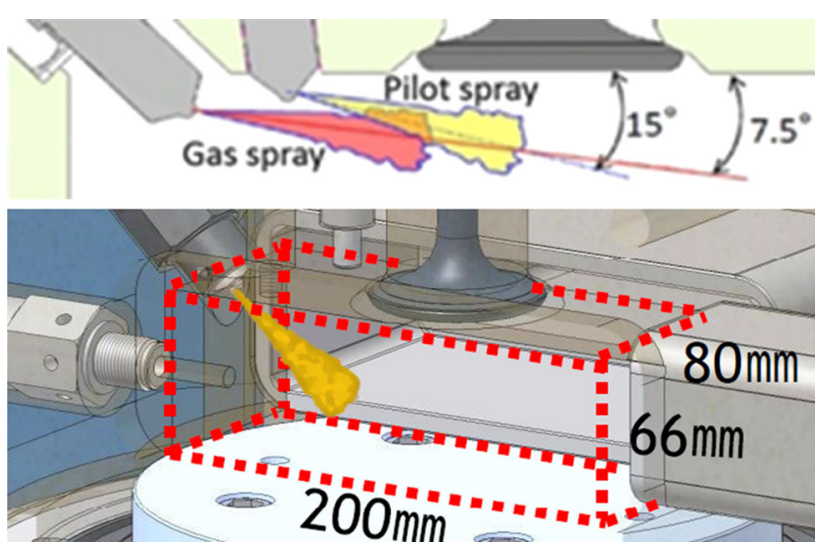

Fig. 2 Combustion chamber for single flame observation described in Sect. 3

Fig. 1 is for the above-mentioned multi-flames investigation by the cylindrical combustion chamber (described in Sect. 4). On the other hand, the cuboid-shaped clearance volume shown in Fig. 2 with a pair of glass windows (200 $\mathrm{mm}$ wide) on both sides allows various optical investigations for the single flame combustion (Sect. 3).

The experimental procedure is as follows. Prior to the experiment, the charge air is pre-heated and pre-compressed in the large air tank shown in Fig. 1. This twostage compression concept allows the experimentation at sufficiently high compression pressure $\left(P_{\mathrm{c}}\right)$ and 


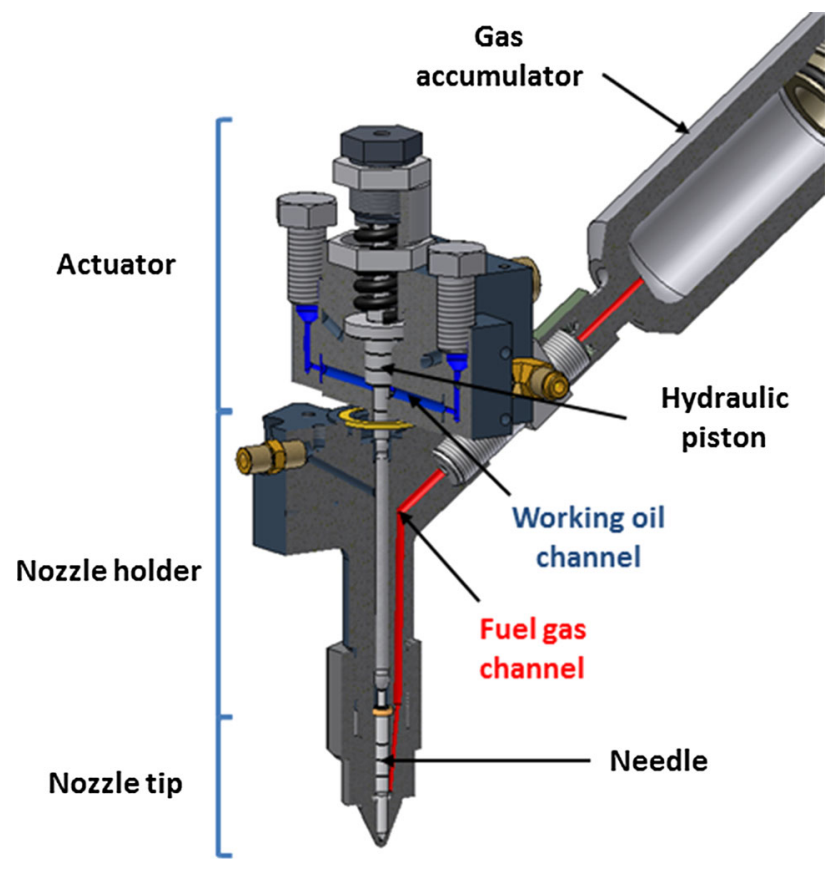

Fig. 3 Gas injector and accumulator

temperature $\left(T_{\mathrm{c}}\right)$ at the combustion, though the compression ratio is fairly low (around 8). Moreover, $P_{\mathrm{c}}$ and $T_{\mathrm{c}}$ can be easily changed depending on the experimental conditions.

The RCEM is a one-shot firing machine: an electric motor accelerates the RCEM to $300 \mathrm{rpm}$, and an intake valve is actuated only once, allowing the pre-heated and pre-compressed air to flow into the cylinder and one real cycle of compression and combustion is carried out. After that, all the burned gas is sent to a gas analyzer and NOx, $\mathrm{CO}$, and $\mathrm{THC}$ can be measured.

Electronically controlled fuel injection systems are utilized, not only for the gas injection but also for the diesel oil pilot injection. The electronically controlled fuel injection system has the merit that any injection timing and duration can be chosen. A gas booster can pressurize the methane up to $50 \mathrm{MPa}$. The gas injector with a gas accumulator is displayed in Fig. 3. The gas accumulator compensates the gas pressure drop during one injection.

Several kinds of optical systems are arranged to obtain precise visualized data. For the single flame, 'shadowgraph' and 'Back Diffused Laser illumination (BDL)' method to visualize the soot cloud within the luminous flame are applied. For the top view of the cylindrical combustion chamber, 'schlieren' technique is tried by utilizing a mirror put on the piston head. That enables to visualize the distributions of high-temperature gas after the combustion. The arrangement of optical systems is explained more in detail in [5].

\section{Results from single flame experiments}

\subsection{Comparison between GI and diesel combustion}

The cuboid-shaped clearance volume shown in Fig. 2 and a pair of glass windows (200 mm wide) on both sides allow various optical investigations for the single flame combustion. At first, the combustion process of GI is compared to the diesel combustion. In this experiment, the gas pressure is set to $30 \mathrm{MPa}$ and an injector nozzle with a diameter of $1.2 \mathrm{~mm}$ is applied. The diesel fuel is injected equivalent to the amount of heat release of GI. Injection pressure of diesel spray is adjusted to set the same injection duration of GI. Air conditions in the cylinder at TDC are set at $P_{\mathrm{c}} 10 \mathrm{MPa}$ and $T_{\mathrm{c}} 550{ }^{\circ} \mathrm{C}$ simulating a real engine.

For the pilot diesel oil (actually a gas oil for automobile is used) injection, $60 \mathrm{MPa}$ injection pressure and a nozzle with a hole of $0.16 \mathrm{~mm}$ diameter are used. As a standard case, the pilot oil is injected before the gas injection. The injected mass of pilot oil is equivalent to $3-4 \%$ of the total released heat. Table 1 lists the injection conditions for comparison of diesel and GI. The estimated air excess ratio is 6.5 in Sect. 3.1 or 7.0 in Sects. 3.2 and 3.3.

A comparison of the rate of heat release (ROHR) and direct photos of flames between GI and diesel combustion is shown in Fig. 4. The injection duration is detected by measuring the displacement of the rod connecting with nozzle needle using a gap sensor. The total heat release is the integral of the heat release rate. The total heat release at $60{ }^{\circ} \mathrm{ATDC}$ is proportional to the amount of burning fuel. Then, the same value of total heat release means that same amount of fuel was injected. In this paper, the experiments were conducted under same heat release to be easily compared in each case. Seeing the direct photos of GI flame set against the diesel flame, the GI combustion process (left) shows a bright pilot flame that successfully ignites the gas-jet at $-4{ }^{\circ} \mathrm{ATDC}$. Thereafter the gas flame outruns the pilot flame and penetrates to the right edge of combustion chamber.

Table 1 Injection condition for comparison of diesel and GI

Pilot injection conditions

\begin{tabular}{lll}
\hline Nozzle hole diameter $(\mathrm{mm})$ & & 0.16 \\
Injection pressure $(\mathrm{MPa})$ & & 60 \\
Injection start/end $\left({ }^{\circ} \mathrm{ATDC}\right)$ & & $-7.5 / 2.8$ \\
\hline Main injection conditions & GI & Diesel \\
\hline Nozzle hole diameter $(\mathrm{mm})$ & 1.2 & 0.5 \\
Injection pressure $(\mathrm{MPa})$ & 30 & 100 \\
Injection start/end $\left({ }^{\circ} \mathrm{ATDC}\right)$ & $-6.0 / 18.0$ & $-5.0 / 18.0$
\end{tabular}



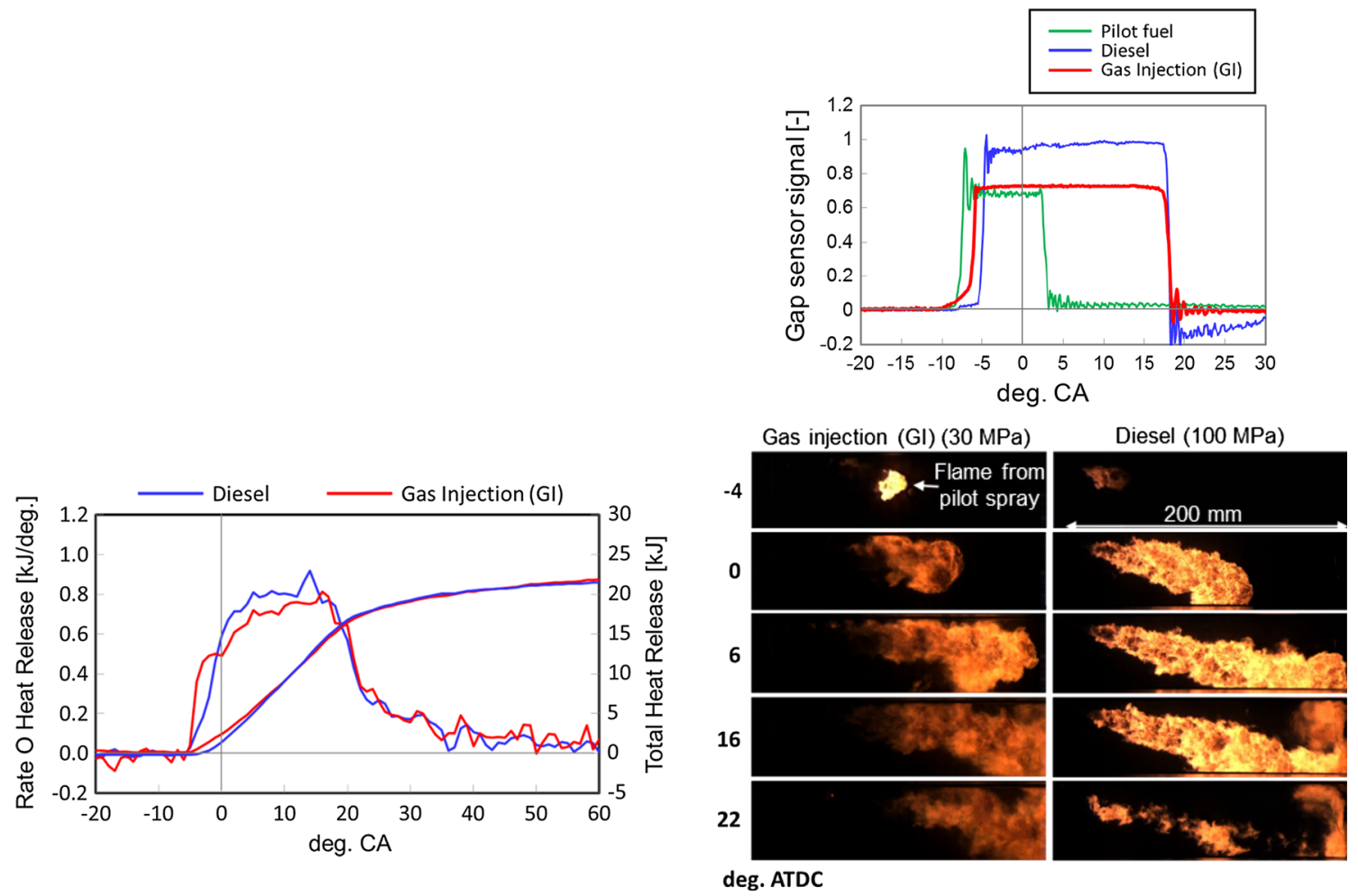

Fig. 4 Comparison between GI and diesel combustion [flame photos (right) and ROHR rate of heat release (left)]

Compared to the diesel flame, the gas flame looks less bright, as expected from the lower $\mathrm{C} / \mathrm{H}$ ratio of methane, and it has a wider flame breadth than the diesel flame. Though the gas injection pressure of $30 \mathrm{MPa}$ is much lower than the diesel injection pressure of $100 \mathrm{MPa}$, the penetration of gas flame is equivalent to the diesel flame, for example at 0 deg. and 6 deg.. A special feature of GI case is that the visible flame looks unable to come up to the injection nozzle side from the ignition point during and after the gas injection.

Though GI and diesel combustion have the differences mentioned above, the ROHR by GI combustion is close to that of the diesel combustion, as seen from Fig. 4. Seeing in detail, ROHR of GI raises steeper just after the ignition, maybe because of the pilot oil combustion. However, the maximum rate is a little smaller in the GI case than the diesel combustion.

In the emission data shown in Table 2, GI combustion emits smaller $\mathrm{CO}$ but higher $\mathrm{HC}$ than the diesel. HC, unburned methane from this experiment is estimated to be about $0.5 \%$ of total injected gas. This is much less than the case of lean-burn gas combustion, where normally 2-3\% methane slip is observed.

As mentioned, the luminosity of GI flame is lower than the luminosity of diesel flame, and proportionally the temperature of GI flame should be lower than the temperature of diesel flame. As shown in Table 2, NOx
Table 2 Comparison of emission data

\begin{tabular}{lcc}
\hline Fuel & \multicolumn{1}{c}{ GI } & Diesel \\
\hline CO (ppm) & $8-10$ & 44 \\
HC (ppm) & $69-87$ & 21 \\
NOx (ppm) & $346-393$ & 531 \\
\hline
\end{tabular}

emission from GI combustion results in about 3/4 of that of the diesel. However, unlike the homogeneous combustion of lean-burn gas engines, the drastic reduction of NOx emission such as $-80 \%$ is impossible.

To demonstrate how clean the GI combustion is, the soot formation in the flame is visualized using the BDL technique mentioned before. Two experiments are carried out. The normal pilot injection is used as the ignition source for the first experiment and a glow plug for the second experiment to eliminate the soot formed by the pilot gas oil. Figure 5 shows the shadowgraph and BDL photos for GI flame in the above-mentioned two cases of ignition sources. The black part of shadowgraph represents the burning area and the black part of BDL photos shows the soot cloud formed in the flame.

Looking at $-1 \mathrm{deg}$. of BDL, it is clear that the pilot flame forms a black soot cloud. At 7 deg., the soot from the pilot flame is pushed by the following gas-jet to the flame front. On the other hand, seeing the case of glow plug ignition at $7 \mathrm{deg}$. where no pilot flame exists, though the 


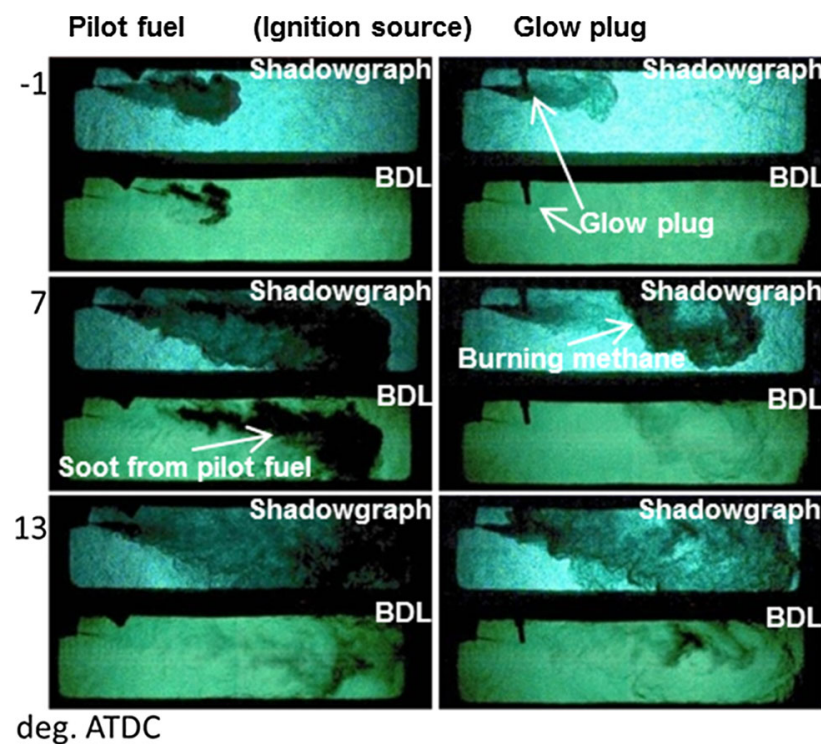

Fig. 5 Shadowgraph and BDL images from GI combustion with pilot injection or glow plug

Table 3 Conditions for different pilot timings

\begin{tabular}{llll}
\hline Pilot injection conditions & \multicolumn{3}{l}{ Pilot injection timing } \\
\cline { 2 - 4 } & Early & Normal & Late \\
\hline Nozzle hole diameter $(\mathrm{mm})$ & 0.16 & & \\
Injection pressure $(\mathrm{MPa})$ & 50 & & \\
Injection start $\left({ }^{\circ} \mathrm{ATDC}\right)$ & -8.0 & -6.0 & -4.4 \\
Injection end $\left({ }^{\circ} \mathrm{ATDC}\right)$ & -4.8 & -1.7 & 0.2 \\
\hline
\end{tabular}

Gas injection conditions

Nozzle hole diameter $(\mathrm{mm})$

1.0

Injection pressure $(\mathrm{MPa})$

27.5

Injection start/end ( ${ }^{\circ}$ ATDC)

$-4.0 / 16.0$

gas is surely burning according to the shadowgraph image, the black color in BDL is very thin. That means the gas-jet is burning well with forming almost no soot cloud.
Table 4 Emmisions data with different pilot timings

\begin{tabular}{lccr}
\hline & \multicolumn{2}{l}{ Pilot injection timing } \\
\cline { 2 - 4 } & Early & Normal & Late \\
\hline CO (ppm) & 12 & 18 & 21 \\
HC (ppm) & 85 & 78 & 100 \\
NOx (ppm) & 223 & 216 & 260 \\
\hline
\end{tabular}

In both shadowgraphs with pilot and glow plug at 13 deg., gas burning flame can be seen in the whole combustion chamber. From the BDL photos at the same timing, it is clear that the gas combustion itself forms only thin soot cloud compared with the pilot flame seen before.

\subsection{Effect of pilot injection timing on GI combustion}

In this study, some effect of pilot injection timing on GI combustion is investigated. The experimental conditions for 'Early', 'Normal' and 'Late' pilot injection timings are summarized in Table 3. The gas injection timing remains unchanged for the three experiments.

The tested three pilot timings and corresponding ROHR (by pilot oil and gas combustion) data are illustrated in Fig. 6. Comparing the early (blue line) and normal (black line) pilot timing, almost no change is found in the ROHR data. On the other hand, the late pilot timing (red line) results in a remarkable high peak in the ROHR, like a diesel knock. According to emission data of Table 4, the late pilot timing causes higher NOx and HC emissions than the other two cases.

The visualized data, shadowgraph images in Fig. 7, reveal these knocking-like phenomena by the late pilot timing. At $-5.5^{\circ} \mathrm{ATDC}$, a small gas-jet just injected from the left edge of combustion chamber can be seen in all three cases, and in the photos of early and normal timing, a pilot spray is also observed. In these two cases, the gas-jet catches up with the pilot flame and is ignited smoothly as visible at $-1.5^{\circ} \mathrm{ATDC}$.
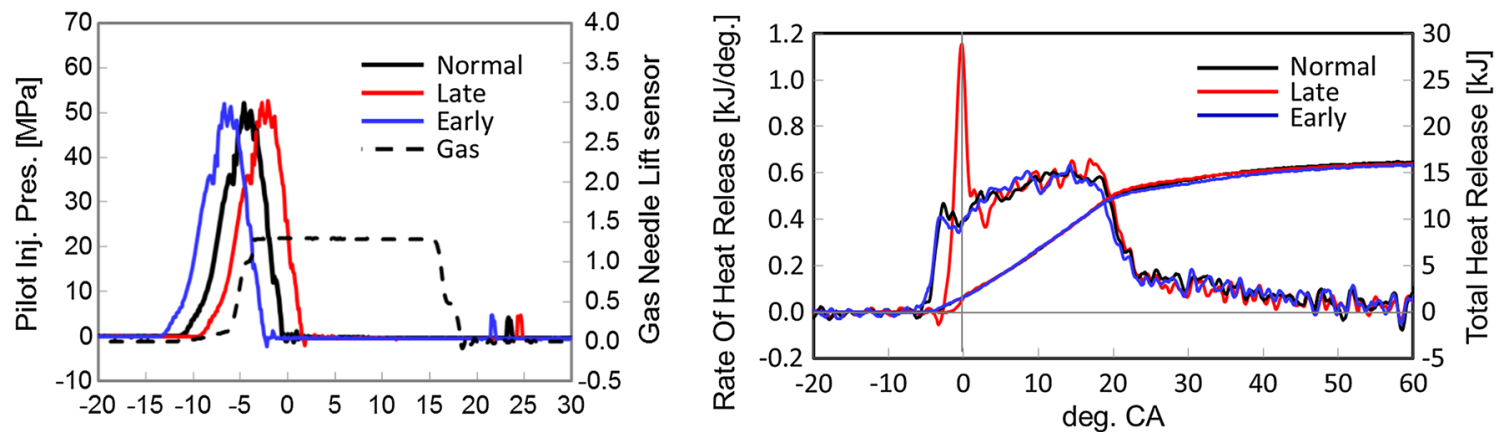

Fig. 6 Three different pilot injection timings (left) and related ROHR (right) 


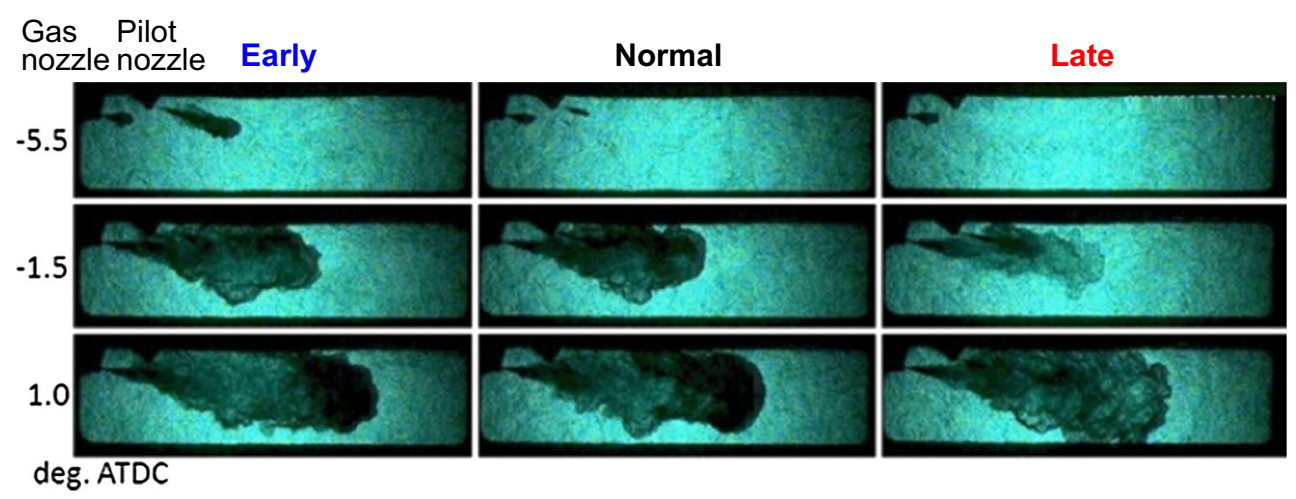

Fig. 7 Visualized data (shadowgraph) with different pilot timings

Table 5 Injection condition for EGR condition

\begin{tabular}{lll}
\hline & Pilot injection conditions & Main injection conditions \\
\hline Nozzle hole diameter $(\mathrm{mm})$ & 0.16 & 1.0 \\
Injection pressure $(\mathrm{MPa})$ & 50 & 27.5 \\
Injection start/end $\left({ }^{\circ} \mathrm{ATDC}\right)$ & $-8.0 /-4.8$ & $-4.0 / 16.0$
\end{tabular}

On the other hand, in the late pilot case, pilot oil is injected into the gas-jet at $-1.5^{\circ} \mathrm{ATDC}$. As an additional bad effect, it would be possible that the pilot spray is covered by the methane that further delays the ignition reactions. After that, the pilot spray ignites the accumulated gas-air mixture and the gas flame expands too fast as seen at $1{ }^{\circ}$ ATDC in Fig. 7. Such phenomena would result in the high peak of ROHR seen in Fig. 6.

Unlike diesel fuel, methane cannot ignite without pilot spray in normal diesel compression engine condition. Then the area of methane-air mixture is increased which can become too lean to burn even somewhere ignited by diesel pilot spray. HC emission was more increased with later pilot ignition. The reason is that the long ignition delay leads to the premixed or rapid combustion by the wellmixed fuel-air mixture. The temperature became high locally by the rapid combustion and this causes that the NO emission was increased.

\subsection{GI combustion simulating EGR condition}

As mentioned, one way to reduce the NOx emission from GI combustion to clear the IMO Tier III NOx regulation is to apply the exhaust gas recirculation (EGR) method. In this study, to clarify the combustion state under the EGR condition, an experiment supplying the air with lower oxygen content is carried out. Oxygen content of the intake air is reduced to $17.5 \%$. Table 5 lists the injection conditions for EGR condition.

In this test, two ways of oxygen $\%$ reduction are tried (Table 6). One is to charge the reduced oxygen air at the
Table 6 Emissions from EGR-like conditions

\begin{tabular}{llll}
\hline Oxygen cont. charge air & $21.0 \%$ & $17.5 \%$ & $17.5 \%$ high pressure \\
Charge air pressure (MPa) & 0.7 & 0.7 & 0.87 \\
CO (ppm) & $14-16$ & 25 & 13 \\
HC (ppm) & $70-87$ & 132 & 136 \\
NOx (ppm) & $459-464$ & 114 & 120 \\
\hline
\end{tabular}

same pressure as the normal (21\% oxygen) air case. Another is that the reduced oxygen air is charged at a higher pressure to compensate the total oxygen mass for the combustion. In Fig. 8, ROHR by the former way is expressed as blue line and the latter as red line, while the normal air case as black line.

According to Fig. 8, both the reduced oxygen cases of blue and red lines show the suppressed maximum ROHR during 10-20 ${ }^{\circ}$ ATDC and afterwards a little higher afterburning rate than the case of normal air. In this figure, the maximum ROHR of red line, the data from higher pressure charge, is unexpectedly still below the data from normal air.

Seeing the emission data in Table 6, above-mentioned both ways of oxygen reduction to $17.5 \%$ successfully contribute to $-75 \%$ NOx decrease. Seeing the effect of high charge pressure on $\mathrm{CO}$ and $\mathrm{HC}$ emissions in Table 6, $\mathrm{HC}$ data show no improvement, while $\mathrm{CO}$ is reduced to the level of normal air case.

The oxygen reduction test is also carried out using the cylindrical combustion chamber and change in the flame behavior is discussed in Sect. 4. 


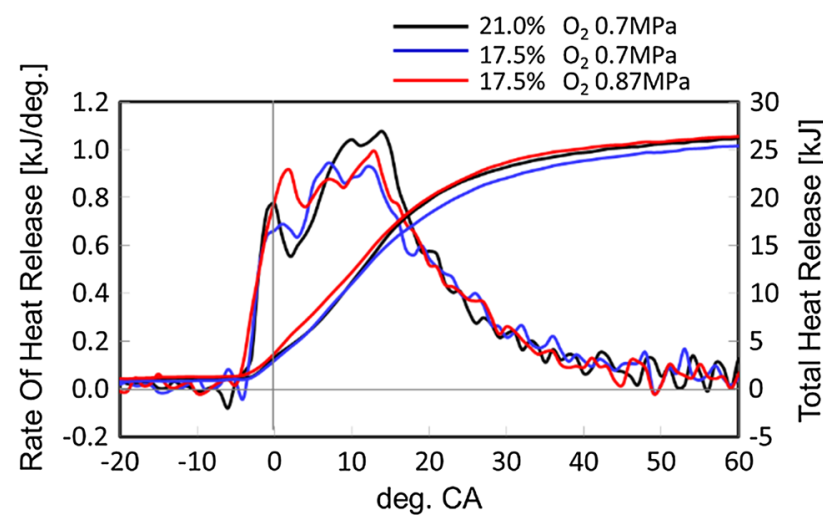

Fig. 8 Change in ROHR by reducing oxygen \% simulating EGR condition

\section{Image of GI combustion in a real engine}

\subsection{Experimental conditions}

To visualize the GI combustion in more realistic conditions, the cylinder head with a cylindrical combustion chamber (Fig. 1) equipped with a glass for whole bore $(240 \mathrm{~mm})$ observation is installed. When air is induced into this combustion chamber from an inclined intake port, swirling flow whose tangential velocity is around $15 \mathrm{~m} / \mathrm{s}$ (measured value at TDC by the PIV method) is generated. This velocity is almost same as in a modern low-speed twostroke diesel engine [4].

A gas injection nozzle with four holes whose injection directions are shown in Fig. 9 is applied simulating the side injection system of two-stroke engines. A pilot injection nozzle with one hole is installed at just upstream position as seen in the figure.

The injection nozzle is tested with four holes of $0.7 \mathrm{~mm}$ diameter. Gas injection pressure is set at $31.5 \mathrm{MPa}$. In this paper, the combination of $0.7 \mathrm{~mm}$ diameter and $31.5 \mathrm{MPa}$ injection pressure is defined as the 'standard' gas injection condition. Experimental conditions are summarized in Table 7. The air condition at compression end is set at $P_{\mathrm{c}} 9 \mathrm{MPa}$ and $T_{\mathrm{c}} 500{ }^{\circ} \mathrm{C}$, which represents a partial load of a real low-speed twostroke GI engine. The estimated air excess ratio is around 8.8 in Sect. 4.

As mentioned in Sect. 2, the schlieren photo technique is applied for detailed observation. The schlieren photos (center) give more information than the direct photos (left) in Fig. 9, the black part downstream of the flame at $16{ }^{\circ}$ ATDC indicates the burned hot gas distribution by the effect of air swirl on the flame.

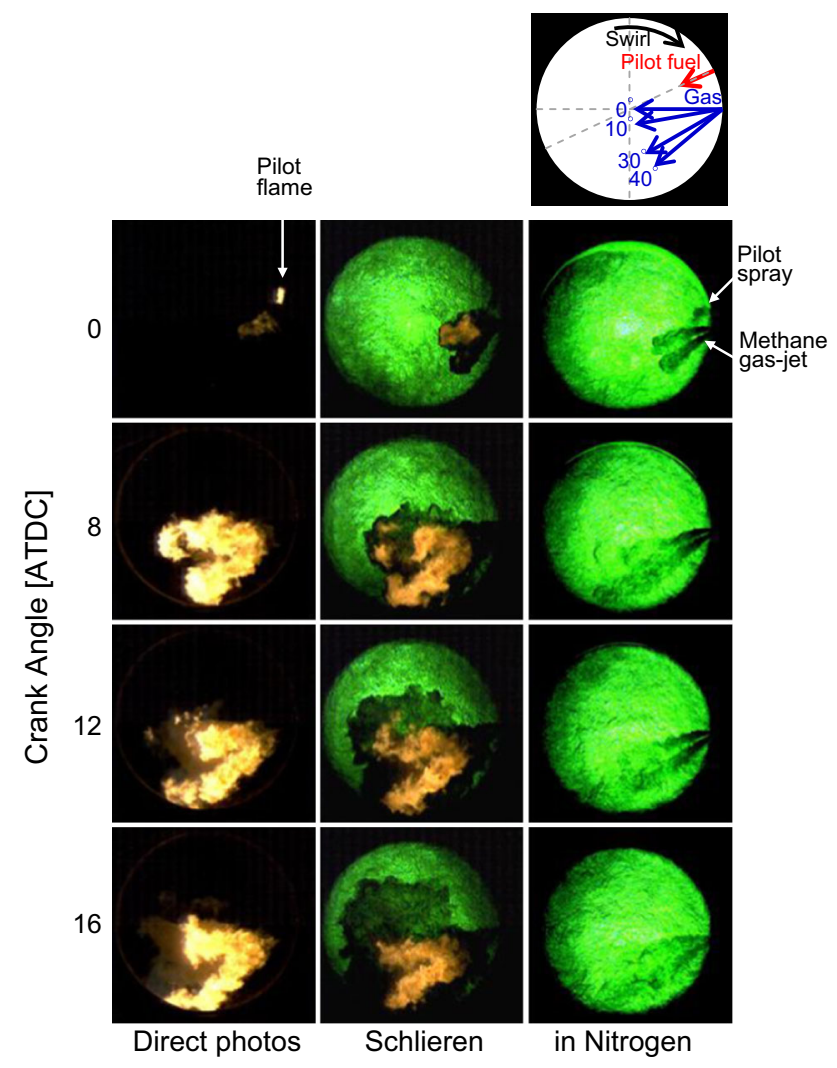

Fig. 9 Photos of GI multi-flames/jets using several optical techniques (gas injection condition: 'standard' in Table 5)

\subsection{Image of GI multiple flames in air swirl}

\subsubsection{Diesel and GI combustion}

Figure 10 shows the schlieren photos of diesel and GI flames. In the left side of the figure, gas oil is injected at a pressure of $135 \mathrm{MPa}$ from the diesel nozzle with four holes of $0.3 \mathrm{~mm}$ diameter. In the center, methane is injected in the above-mentioned 'standard' condition into the normal air. Photos in the right side are GI flames in the air with lower oxygen (17.3\%) simulating the EGR condition.

Comparing the diesel flame (left) and GI flame in the normal air (center), difference in the brightness of flames is seen like the single flame photos in Fig. 4. Moreover, the diesel flame with strong penetration is less affected by the swirl flow from 8 to $12^{\circ} \mathrm{ATDC}$ compared to the GI case. However, as little difference in the distribution of burned gas, the black part downstream from the flame, is found at 16 and 20 deg., it is not concluded that the optimum swirl intensity is different between for diesel and GI combustion. 
Table 7 Experimental conditions for cylindrical combustion chamber

\begin{tabular}{llll}
\hline Air conditions at injection start & \multicolumn{2}{l}{ Pilot injection conditions } \\
\hline Compression pressure & $9.0 \mathrm{MPa}$ & Nozzle hole diameter & $0.2 \mathrm{~mm} \times 1$ \\
Compression temperature & $773 \mathrm{~K}$ & Injection pressure (MPa) & 50 \\
\hline Main injection conditions & Injection start/end $\left({ }^{\circ} \mathrm{ATDC}\right)$ & $-8.0 /-4.8$ \\
\hline Nozzle hole diameter $(\mathrm{mm})$ & & \\
Injection pressure $(\mathrm{MPa})$ & & $0.7 \mathrm{~mm} \times 4$ \\
Injection start/end $\left({ }^{\circ} \mathrm{ATDC}\right)$ & & 31.5 \\
\hline
\end{tabular}

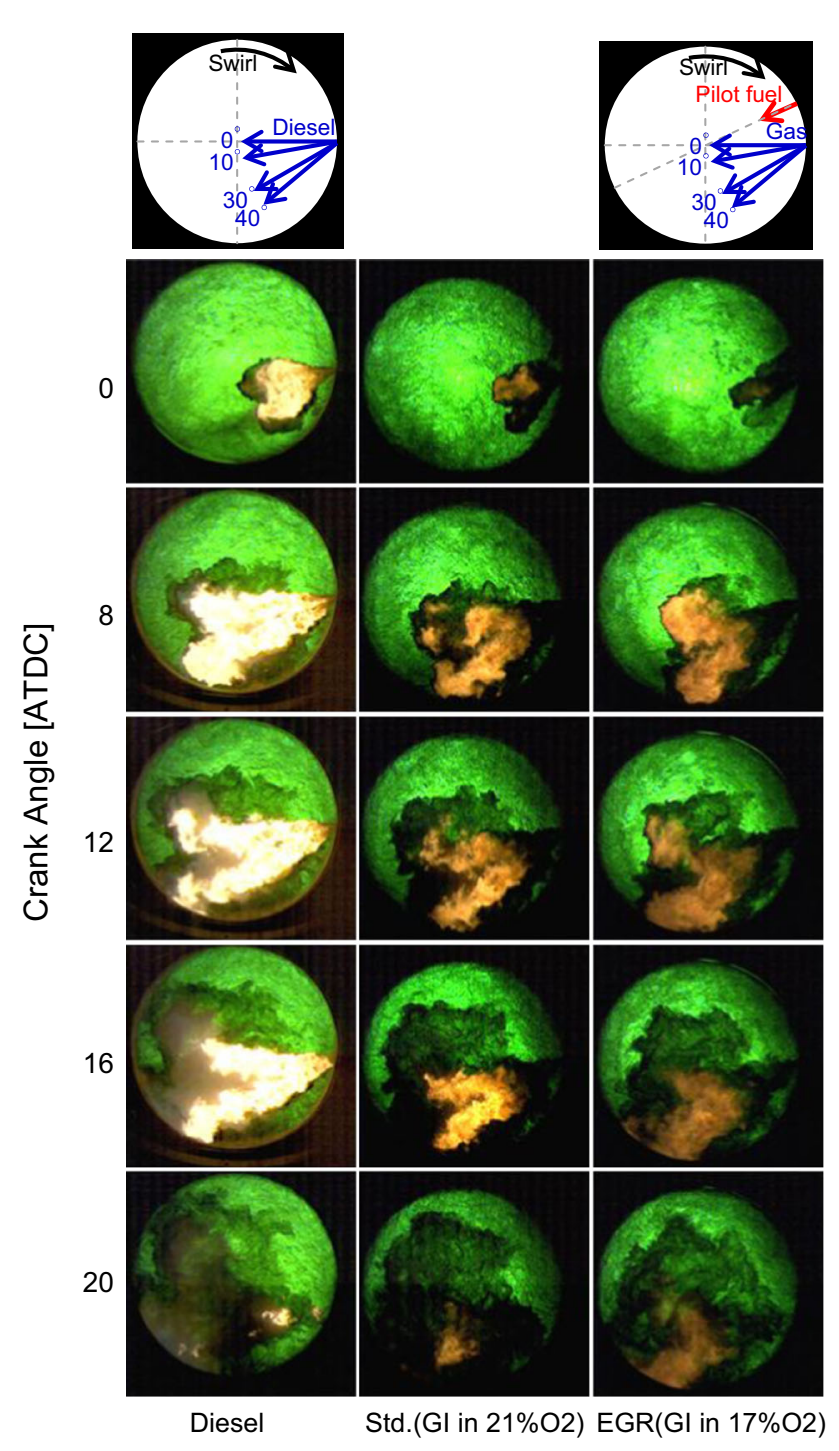

Fig. 10 Visualized multi-flames using schlieren photo technique (diesel and GI)

Figure 11 shows a comparison of ROHR between the two fuels. In this figure, the diesel combustion shows a higher premixed combustion peak just after the self-ignition, not seen in Fig. 4 for the single spray. It is only because $T_{\mathrm{c}}$ (air temperature at ignition) is $50{ }^{\circ} \mathrm{C}$ lower and the ignition delay is longer than the case of Fig. 4. Nevertheless, it is understood that the GI flames are ignited just after the injection according to the ROHR in Fig. 11, thanks to the pilot injection at a proper timing. Seeing Fig. 11 more in detail, though the injection end timings for both fuels are just the same, the ROHR of GI shows slightly longer combustion duration than the diesel combustion.

Emission data are shown in Table 8. The GI combustion (standard) emits two times more $\mathrm{CO}$, ten times more $\mathrm{HC}$ but $40 \%$ less NOx than the diesel combustion in this experiment. The reason of such a high unburned HC from the GI combustion is discussed. In Fig. 4, a special feature that the visible flame looks unable to come up to the injection nozzle side from the ignition point during and after the gas injection is seen only in the GI case. Just the same feature is also seen in Fig. 10. This unburned part near the injection nozzle is considered to contain too rich methane to burn and would be an origin of the high $\mathrm{HC}$ emission.

\subsubsection{EGR effect on GI multi-flames}

The GI flame in lower oxygen \% (named 'EGR' condition) is compared to the case of normal air $\left(21 \% \mathrm{O}_{2}\right)$ in Fig. 10 . The flame in the former looks less bright than in the latter at 12 and $16^{\circ} \mathrm{ATDC}$, depending on the combustion temperature. Comparing the ROHR in Fig. 12, the lower oxygen case shows a slower rising up of combustion just after the ignition and a slightly longer after-burning.

According to the emission data in Table 8 , a drastic $-85 \%$ NOx reduction (from 300 to $44 \mathrm{ppm}$ ) is obtained by oxygen reduction from $21 \%$ (standard) to $17.3 \%$ (EGR), and comparing to the diesel case, it is counted that NOx reduction to $10 \%(-90 \%)$ is possible by converting a diesel engine to 'GI plus EGR' mode.

\section{CFD simulation}

The simulation of GI was conducted to understand the GI combustion. However, the phenomena are complicated and different from the conventional diesel spray and combustion. 

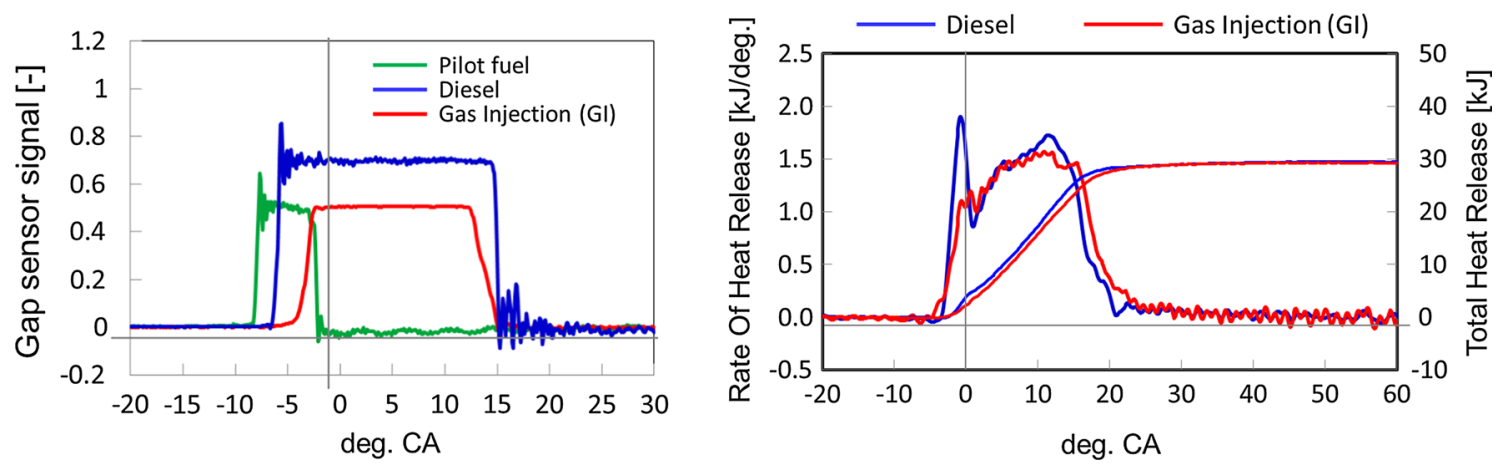

Fig. 11 Diesel and GI injection duration (left) and rate of heat release (ROHR) (right)

Table 8 Emissions from multi-flame experiments

\begin{tabular}{lllr}
\hline Experiment & Diesel & Standard & EGR \\
\hline CO $(\mathrm{ppm})$ & 16.6 & 30.2 & 45 \\
HC $(\mathrm{ppm})$ & 11 & 125 & 155 \\
NOx $(\mathrm{ppm})$ & 499 & 300 & 44 \\
\hline
\end{tabular}

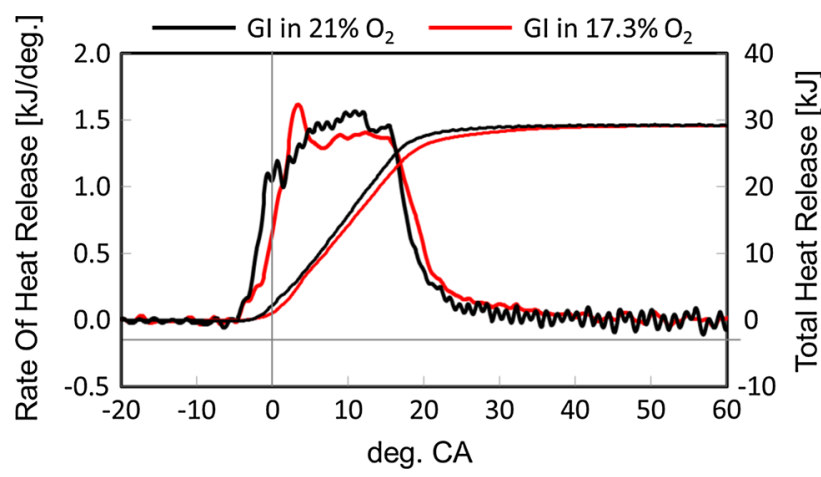

Fig. 12 Change in ROHR by reducing oxygen \% in air

For that reason, a new numerical model was developed and combining the three-dimensional code, KIVA3V [6], and the software tool for solving complex chemical kinetics, SENKIN [7]. The KIVA code is widely applied for numerical simulations of both diesel and gasoline engines. However, it is difficult for conventional KIVA code to simulate the combustion of gas injection engines because two kinds of fuels were injected and burnt simultaneously in the combustion chamber. The conventional combustion model could not calculate multi-component fuels. Then the SENKIN code is used in this calculation. It calculates the time evolution of a homogeneous reacting gas mixture in a cell based on reaction mechanism. To simulate transient direct injection of gaseous fuel with lower calculation cost, Gas Parcel model was used in this study. This model treats gaseous fuel injection as a group of gaseous sphere. This model can calculate gas injection by a Lagrangian-Eulerian approach of diesel spray simulation. The spray consisting of gaseous spheres was calculated in the same way as diesel spray.
By exchanging momentum and mass between the gas parcel and ambient fluid, the motions of gas parcels can reflect the ambient fluid. The mass transportation rate between the gas parcel and ambient fluid is assumed to be proportional to the mass of the gas parcels. Equation 1 shows mass transportation rate from gas parcels to ambient per unit time.

$\frac{\mathrm{d} m_{\mathrm{p}}}{\mathrm{d} t}=-\frac{m_{\mathrm{p}}}{\tau_{\mathrm{p}}}=-\frac{\pi d_{\mathrm{p}}^{3} \rho_{\mathrm{p}} N_{\mathrm{p}}}{6 \tau_{\mathrm{p}}}$,

where $m_{\mathrm{p}}, \rho_{\mathrm{p}}, d_{\mathrm{p}}$ represents mass of one parcel, density of gaseous sphere and droplet diameter, respectively. $N_{\mathrm{p}}$ is the number of droplets in a parcel and $\tau_{\mathrm{p}}$ is model constant related to lifetime of the gas parcels. Equation 1 was solved with Euler's difference method. The amount of mass was added to mass conservation equation as a source term. The density of gaseous sphere is decreased as shown in Eq. 2 after the mass of parcel was transported to ambient.

$\frac{\mathrm{d} \rho_{\mathrm{p}}}{\mathrm{d} t}=-\frac{1}{V_{\mathrm{p}}} \frac{\mathrm{d} m_{\mathrm{p}}}{\mathrm{d} t}$.

The initial velocity, density and diameter of gaseous parcel at injection were decided by injection pressure and temperature of gas and diameter of nozzle hole. The diameter of nozzle hole was calculated to an equivalence diameter according to Eq. 3. The equivalence diameter is assumed to be equivalent to the diameter of nozzle hole for diesel spray. All properties of droplets such as density and velocity have to be regarded

$D_{\text {eq }}=\left(\rho_{\mathrm{g}} / \rho_{1}\right) D_{\mathrm{g}}$,

where $\rho_{\mathrm{g}}, \rho_{1}$ represent density of gas fuel and density of liquid fuel, respectively. $D_{\mathrm{eq}}, D_{\mathrm{g}}$ are the equivalence diameter and the diameter of nozzle hole.

Table 9 shows calculation model used in this study. Simulation and experiment were conducted according to Table 10 using the RCEM shown in Sect. 3.1. Table 10 shows the initial condition and injection condition for 
Table 9 Calculation model list

\begin{tabular}{ll}
\hline Phenomenon & Calculation model \\
\hline Turbulence & RNG $k-\varepsilon$ model \\
Primary break-up & Blob model \\
Secondary break-up & KH-RT model \\
Combustion & SENKIN \\
Reaction & Gas oil ERC $n$-heptane scheme [8] \\
& Methane GRI-Mech 3.0 [9] \\
NO emission & Extended Zeldovich model \\
\hline
\end{tabular}

simulation and experiment. Initial pressure was changed to keep the oxygen mass with reduction of oxygen concentration. The number of cells used in this simulation is about 100,000 at BDC. Minimum cell size is $5 \times 4 \times 4 \mathrm{~mm}$.

Figure 13 shows the injection mass profile with each injection for this calculation. Injection profile of calculation was simplified to easily compare the results of simulation. Figure 14 shows the experimental and calculated values of $\mathrm{NO}$ emission results with changing the oxygen concentration in GI combustion. Experimental values are shown by solid squares and solid rectangles. The line in the graph was obtained from calculation results. The NO emission was decreased with decreasing oxygen concentration. This tendency is same as the conventional diesel diffusive combustion. The $\mathrm{HC}$ emission was increased and $\mathrm{CO}$ was not changed with decreasing oxygen concentration. This tendency is the same as the results shown in Sect. 3.3. Therefore, the emission from GI diffusive combustion can be reproduced by introducing the Gas Parcel model. The calculated temperature distribution of GI and diesel flame in the cuboid-shaped combustion chamber of RCEM is shown in Fig. 15. The flame temperature measurement using the two-color method can not apply for GI flame and then the calculated temperature distribution data was used in this study. This figure shows the calculated gas temperature distributions for the three cases, GI flame in

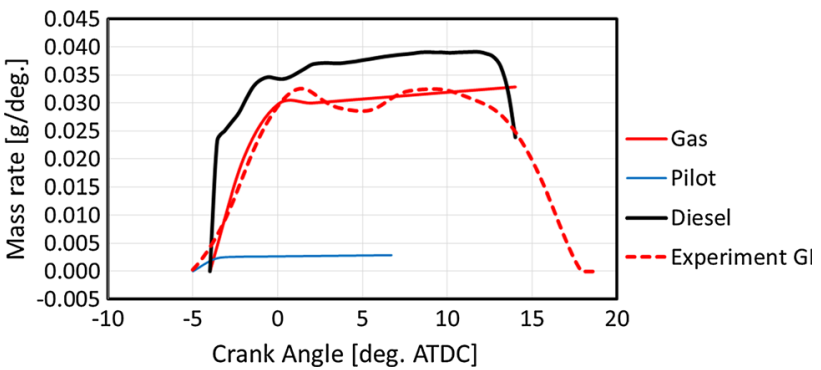

Fig. 13 Input injection profiles for calculation

the air with $21 \%$ oxygen, GI in the air with $17 \%$ oxygen and diesel flame in the air. The high-temperature area which colored red in the GI flame with $17 \%$ oxygen is reduced compared to the area with $21 \%$ oxygen. Moreover, the high-temperature area in GI combustion was reduced compared to the diesel combustion. The reason is that the adiabatic flame temperature of GI combustion is lower than that of diesel combustion in same equivalence ratio condition. $\mathrm{C} / \mathrm{H}$ ratio of methane is higher than that of diesel. The temperature of GI combustion is harder to be increased due to the higher ratio of water in exhaust gas. Lower temperature leads to lower NOx emission by extended Zeldovich mechanism. This calculated result is reasonable in the point that GI combustion can reduce NO emission in comparison to diesel combustion.

From all the temperature distributions, some difference in the temperature distribution near the injection nozzle (at the left edge of combustion chamber) between GI and diesel, seen in the experiment results, is simulated.

\section{Conclusions}

In this study, the rapid compression and expansion machine (RCEM) makes it possible to investigate the gas jet combustion in detail.

Table 10 Calculation and experimental condition

\begin{tabular}{|c|c|c|c|c|c|}
\hline \multicolumn{2}{|c|}{ Initial condition $\left(-142{ }^{\circ} \mathrm{ATDC}\right)$} & \multicolumn{4}{|l|}{ Injection condition } \\
\hline Pressure (MPa) & $0.81,0.73,0.65$ & & Pilot & Gas & Diesel \\
\hline Temperature & $423 \mathrm{~K}$ & Nozzle hole diameter & $0.16 \mathrm{~mm}$ & $1.6 \mathrm{~mm}$ & $0.5 \mathrm{~mm}$ \\
\hline \multirow[t]{3}{*}{ Oxygen concentration } & $17.0,19.0,21.0 \%$ & Inj. start $\left({ }^{\circ} \mathrm{ATDC}\right)$ & $60 \mathrm{MPa}$ & $30 \mathrm{MPa}$ & $150 \mathrm{MPa}$ \\
\hline & & Inj. duration & $11 \mathrm{deg}$. & $18 \mathrm{deg}$. & $18 \mathrm{deg}$. \\
\hline & & Inj. start ( $\left.{ }^{\circ} \mathrm{ATDC}\right)$ & -5 & -4 & -4 \\
\hline TDC condition & & Inj. mass & $31 \mathrm{mg}$ & $0.54 \mathrm{~g}$ & $0.642 \mathrm{~g}$ \\
\hline Pressure (MPa) & $12.5,11.2,10.0$ & Equivalence ratio (-) & 0.0068 & 0.1387 & 0.1408 \\
\hline \multirow[t]{3}{*}{ Temperature } & $820 \mathrm{~K}$ & Fuel & $n$-Heptane & Methane & $n$-Heptane \\
\hline & & Chemical species & 29 (ERC) & 22 (GRI-MECH) & 29 (ERC) \\
\hline & & Chemical reaction & 52 & 84 & 52 \\
\hline
\end{tabular}



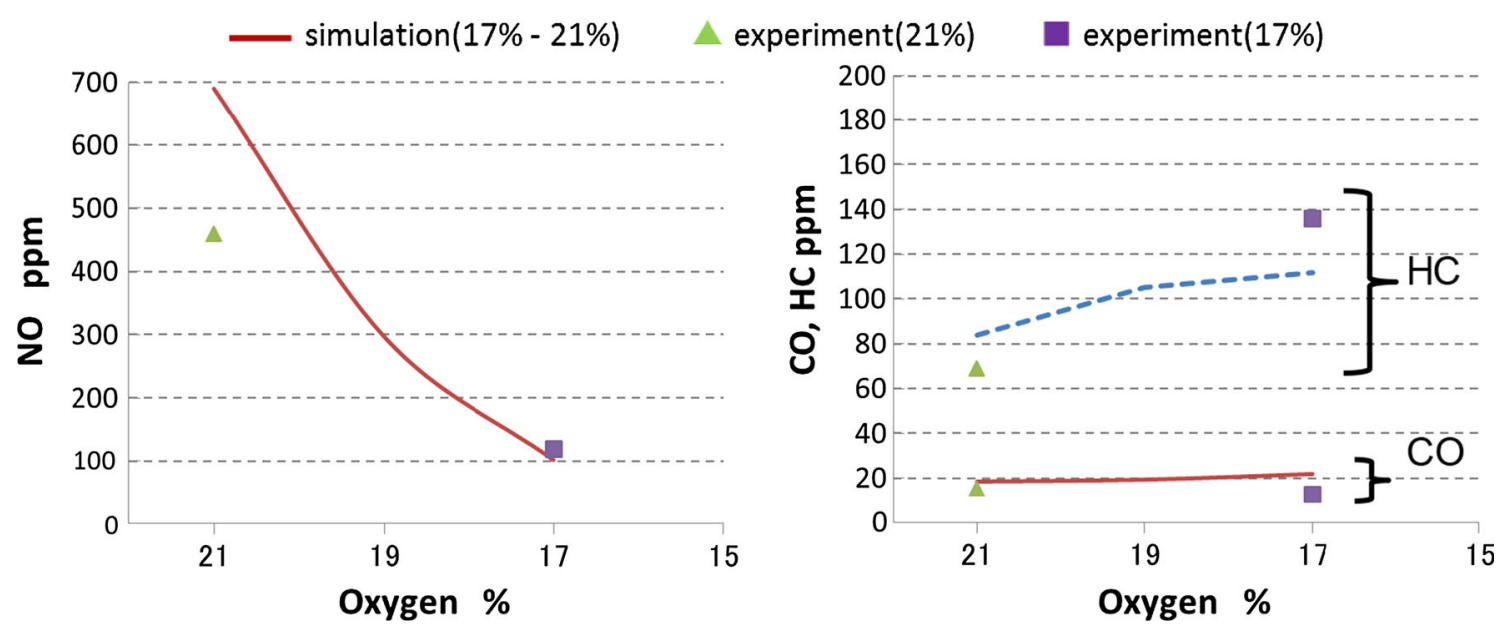

Fig. 14 Comparison of experimental calculated emission results with changing oxygen concentration

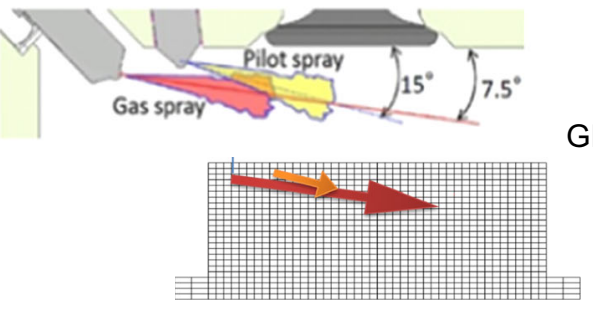

$\mathrm{GI}$ in $21 \% \mathrm{O}_{2}$

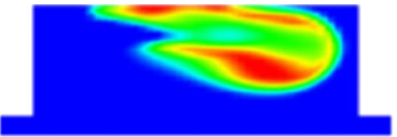

(A model simulating the blokish-shaped combustion chamber of RCEM)

Diesel

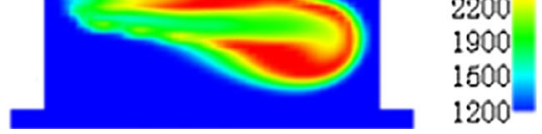

Fig. 15 Computational mesh (left) and an example of CFD result on combustion temperature distribution (right)

First, comparing with the diesel combustion, the GI flame burns with a similar heat release rate to the diesel flame, while the soot formation in gas flame is clearly smaller than that in the diesel flame. NOx emission from GI is also decreased by about $30 \%$ compared to that of the diesel combustion.

Late micropilot injection timing causes higher THC emission due to increased premixed combustion. Early micropilot injection timing is not effective to the RHOR and $\mathrm{HC}$ emission and $\mathrm{NO}$ emission.

In the case of lower oxygen condition (17.5\%), NO emission is reduced by $75 \%$ similar to diesel combustion. However, HC emission is increased by $65 \%$.

Changing the combustion chamber to the cylindrical shape simulating a real two-stroke GI engine, effect of gas injection pressure and gas injection hole diameter is investigated. The same trends with single cylinder concerning ROHR and emission data are obtained.

The 3D CFD code KIVA3V combined with SENKIN was modified for GI combustion to simulate gas injection based on Lagrangian-Eulerian approach. As a result of calculation, it was confirmed that the gas temperature of GI case in $17 \%$ oxygen is roughly $100-200{ }^{\circ} \mathrm{C}$ lower than the gas temperature of GI case in $21 \%$ oxygen.

Acknowledgements Special thanks to Mitsui Engineering and Shipbuilding Co., Ltd., Japan, for supporting this project.

Open Access This article is distributed under the terms of the Creative Commons Attribution 4.0 International License (http://crea tivecommons.org/licenses/by/4.0/), which permits unrestricted use, distribution, and reproduction in any medium, provided you give appropriate credit to the original author(s) and the source, provide a link to the Creative Commons license, and indicate if changes were made.

\section{References}

1. Fukuda T, Ohtsu M, Hanafusa M, Pedersen PS, Grone O, Schnohr O (1995) Development of the world's first large-bore gas-injection engine. In: 21 st CIMAC Interlaken

2. Juliussen L, Kryger M, Andreasen A (2011) MAN B\&W ME-GI engines, recent research and results. In: International symposium on marine engineering (ISME), Kobe

3. Miyake M, Biwa T, Endoh Y, Shimotsu M, Murakami S, Komoda T (1983) The development of high output, highly efficient gas burning diesel engines. In: 15th CIMAC, Paris 
4. Mayer S, Hult J, Nogenmyr K, Clausen S (2013) Advanced optical development tools for two-stroke marine diesel engines. In: 27th CIMAC, Shanghai, Paper No. 53

5. Imhof D, Tsuru D, Tajima H, Takasaki K (2013) High-pressure natural gas injection (GI) marine engine research with a rapid compression expansion machine. In: 27th CIMAC, Shanghai, Paper No. 12

6. Amsden AA (1999) KIVA3V, Release 2, Improvement to KIVA3V. Los Alamos National Laboratory Report LA-13608-MS
7. Luz AE, Kee RJ, Miller JA (1988) SENKIN: a FORTRAN program for predicting homogeneous gas phase chemical kinetics with sensitivity analysis. Sandia National Laboratories Report, SAND 87-8248

8. Patel A, Kong S, Reitz R (2004) Development and validation of a reduced reaction mechanism for HCCI engine simulations, SAE2004-01-0558r

9. GRI-Mech 3.0 (Online). http://www.me.berkeley.edu/gri_mech/. Accessed 14 Dec 2012 